\title{
Tobacco Use and its Dental Implications: A Review
}

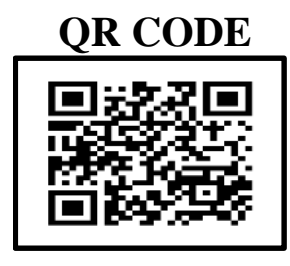

\section{KESARI SINGH*1, KHATEEB KHAN²}

Use of tobacco can be attributed to oral diseases and disorders like oral cancer, periodontal disease, caries and gingival recession along with various other benign mucosal disorders as well as failure of implants. The need for specific attention is given to the impact of tobacco cessation on oral health outcomes. This review concluded that severe robust epidemiologic evidence exists for the adverse oral health effects of tobacco smoking and other types of tobacco use.

KEYWORDS: Smoking, Oral Cancer, Periodontal disease, Implants, Dental Caries

\section{INTRODUCTION}

Although much has been done to educate and motivate people to stop smoking as a habit via various medias, there are people who are still doing this social evil. Researchers, over the years, demonstrated a direct association between smoking and degradation of one's general and oral health. ${ }^{1-3}$ The use of tobacco kills nearly 6 million people each year and this could rise to 8 million by 2030, if the consumption patterns do not reduce drastically by further strengthening efforts at a grass-root level. ${ }^{3}$

Tobacco is abused in a number of ways, with its smoked form being fairly common and its consumption varies as per geographic location, demographics and practices related to tobacco. Many populations also use smokeless tobacco, which is of basic two forms; snuff (that is finely ground or cut tobacco leaves that can be dried or moist, loose or portion packed in sachet) and chewing tobacco (loose leaf, in pouches of tobacco leaves, in twisted form. ${ }^{5,6}$ This review paper was written with the aim to present a brief literature review for medical and dental practitioners on the effect of tobacco smoking on oral and periodontal health, particularly on dental implants, and oral cancers.

\section{Tobacco Smoking and Periodontal Diseases}

Periodontal diseases, such as gingivitis and periodontitis, are the most common kinds of human bacterial infections affecting the gingiva and bones supporting the teeth, leading to its rapid destruction.
In a recent conventional systematic review on periodontal disease and smoking, it was concluded that the evidence in support of a negative effect of smoking on periodontal health is strong. The review was based upon an appraisal of 70 crosssectional studies and 14 case-control studies, all of which indicated towards an association between smoking and periodontal disease, and furthermore, 21 cohort studies of which 20 pointed out in the direction of the above mentioned results. ${ }^{7}$

Various epidemiological studies have concluded that tobacco use is a significant risk factor for inducing periodontal diseases. ${ }^{9,10}$ The studies also state that disease severity also increases with the frequency of smoking.10 Smokers accumulate markedly more dental calculus than non-smokers do, and the quantity of calculus is also correlated with the frequency of smoking.9,11 Of many smoking related periodontal diseases, Acute necrotizing gingivitis(ANUG) is strongly correlated with tobacco use. ${ }^{12}$

\section{Periodontal Effects of Smoking Cessation Smoking cessation is extremely beneficial to periodontal treatment outcomes and oral health and mostly, the damage done is reversible i.e the oral mucosa repairs itself. Smoking cessation may even restore the periodontal and microbial healing response back to normal: the healing response of ex-smokers can even become similar to non- smokers. ${ }^{13}$ Smokers who have been treated for periodontal diseases should be recalled more and more frequently for professional examination,}


reinforcement of oral hygiene instruction, intensive periodic scaling, and prophylaxis after completion of treatment. A perfect combination of antibiotic therapy and participation in a smoking cessation programme may be the most effective and efficient treatment of smoking induced periodontal diseases in an individual. ${ }^{14}$

\section{Dental Implant Failure}

An addiction to smoking has a direct relation to dental implant failure, ${ }^{15}$ and there is a general consensus among clinicians on the negative effect of smoking on implant survival or success. Significantly greater proportions or numbers of implant failures occur in smokers than in nonsmokers (11.28\% versus $4.76 \%) .{ }^{16}$ Enrollment in a suitable tobacco cessation programme has been seen to improve the success rate of osseointegration of implants in smokers who overcome the addiction, with significant differences between failure rates between non-smokers and smokers. ${ }^{17}$

\section{Oral Precancerous Lesions}

Leukoplakia and Erythroplakia:

In a case-control study (Shiu et al.) showed that the adjusted ratio for betel nut chewing and smoking on the occurrence of leukoplakia were 17.43 and 3.22. These findings showed that smoking cessation may reduce the number of leukoplakia cases by $36 \%$, while stopping chewing of betel nut may influence prevent $62 \%$ cases of leukoplakia and $26 \%$ of cases of malignant transformation to oral cancer or carcinoma. ${ }^{18}$

\section{Oral Cancer}

Oral cancer is majorly dominated by developing into squamous cell carcinoma, which is present in 90\%-95\% of all oral cancers; the role of tobacco in the development of oral squamous cell carcinoma is well known.9 Countless researchers have time and again sated that tobacco use (also considering reverse smoking, chewing of betel leaves, use of smokeless tobacco significantly) increases the risk of cancers of the upper aero digestive tract.

\section{Dental Caries}

Few cross-sectional studies have studied the relationship between smoking and dental caries and an example is of the study of military soldiers from Illinois (mean age $=\mathbf{2 5} .9$ years), in which it was documented that smokers had a higher number of untreated decaying teeth, missing surfaces and total DMFS than non-smokers.19 However, no information was obtained regarding diet consumed or oral hygiene practices of the patients, which could have served as a confounding factor.

\section{Smoking Cessation Strategies}

Smoking is a chronic condition that requisites longterm management with the results of providing dental treatment being questionable at times. For smokers, another factor to keep in mind is the increased financial burden due to a possibility of failed dental treatments. Efforts on cessation of smoking are divided into two broad categories: pharmacological and behavioural.

Pharmacological approach includes two general strategies: a). nicotine replacement (NRT) and b) bupropion therapy (non- NRT). The use of Nicotine Replacement Therapy reduces physical withdrawal signs and symptoms. Nicotine gum, transdermal patch, inhalers, nasal sprays, sublingual tablets, and lozenges are examples of NRT products available in the market to help in quitting smoking. ${ }^{20}$

Bupropion is the first prescribed non-nicotine pharmacological agent shown to be effective and efficient for smoking cessation, and it has been approved by the United States Food and Drug Administration for that purpose. It is an antidepressant that influences on dopaminergic pathways in the central nervous system. The combination of both bupropion with NRT via a transdermal system has the highest success rate of cessation treatments. ${ }^{21}$

In addition, the success of smoking cessation using pharmacotherapy-based treatment can be increased when it is accompanied by individual or group-based behavioral therapy programmes conducted by specialized counsellors.

\section{CONCLUSION}

Periodontal diseases, oral cancers, dental implant failure, and precancerous development are linked very closely with the tobacco use. Advising patients to quit tobacco abuse is a dental professional's responsibility, and the dentists may take an active and competent role in nicotine replacement counselling of the patient. Smoking cessation should be incorporated as an integral teaching 
component of the undergraduate dental curriculum in colleges, particularly with respect to the prevention and diagnosis of tobacco-induced oral lesions and complications associated with it.

\section{REFERENCES}

1. Centers for Disease Control and Prevention (US); National Center for Chronic Disease Prevention and Health Promotion (US); Office on Smoking and Health (US). How Tobacco Smoke Causes Disease: The Biology and Behavioral Basis for Smoking-Attributable Disease: A Report of the Surgeon General. Atlanta (GA): Centers for Disease Control and Prevention (US); 2010. 7, Pulmonary Diseases. Available from: https://www.ncbi.nlm.nih.gov/books/NBK53021/

[Accessed online on 15th August,2018]

2. Schane RE. Ling PM, Glantz SA. Health Effects of Light and Intermittent Smoking: A Review. Circulation. 2010 April 6; 121(13): 1518-1522.

3. Singh CR, Kathiresan K. Effect of cigarette smoking on human health and promising remedy by mangroves. Asian Pacific Journal of Tropical Biomedicine 2015;5(2):162-7.

4. Brodeur JM, Payette $M$, Benigeri $M$, Charbonneau A, Olivier M, Chabot D. Periodontal diseases among Quebec adults aged 35 to 44 years. J Can Dent Assoc 2001; 67(1):34.

5. Shafey O, Eriksen M, Ross H, et al. The Tobacco Atlas. 3rd edn. Atlanta, USA: American Cancer Society, 2009.Google Scholar

6. Your oral health: what is oral health? J CanDent Assoc, 2005.

7. Bergstrom J. Periodontitis and smoking: an evidence-based appraisal. J Evid Based Dent Pract 20066 1: 33-41.

8. Bergstrom J. Cigarette smoking as risk factor in chronic periodontal disease. Community Dent Oral Epidemiol 1989;17:245-7.

9. Yadav T, Raghav J. Tobacco, the irritant of oral mucosa: A review Tricity J Healthcare Res 2017;1(1):2-6.

10. Amarasena N, Ekanayaka AN, Herath L, Miyazaki $\mathrm{H}$. Tobacco use and oral hygiene as risk indicators for periodontitis. Community Dent Oral Epidemiol 2002;30:115-23.

Source of support: Nil, Conflict of interest: None declared
11. Neto JBC, Rosa EF, Pannuti CM, Romito GA. Smoking and periodontal tissues: a review. Braz Oral Res. (São Paulo) 2012;26(Spec Iss 1):25-3.

12. Sreedevi M, Ramesh A, Dwarakanath C. Periodontal Status in Smokers and Nonsmokers: A Clinical, Microbiological, and Histopathological Study. International Journal of Dentistry 2012;2012:571590.

13. Kaldahl WB, Johnson GK, Patil KD, Kalkwarf KL. Levels of cigarette consumption and response to periodontal therapy. J Periodontol 1996; 67:67581.

14. Winkel EG, Van Winkelhoff AJ, Timmerman MF, Van der Velden U, Van der Weijden GA. Amoxicillin plus metronidazole in the treatment of adult periodontitis patients. A double-blind placebo-controlled study. J Clin Periodontol 2001;28:296-305.

15. Widmark G, Andersson B, Carlsson GE, Lindvall AM, Ivanoff CJ. Rehabilitation of patients with severely resorbed maxillae by means of implants with or without bone grafts: a $3^{-}$to $5^{-}$ year follow-up clinical report. Int J Oral Maxillofac Implants 2001;16:73-9.

16. Bain CA, Moy PK. The association between the failure of dental implants and cigarette smoking. Int J Oral Maxillofac Implants 1993; 8:609-15.

17. Bain CA. Smoking and implant failure-benefits of a smoking cessation protocol. Int $\mathrm{J}$ Oral Maxillofac Implants 1996;11:756-9.

18. Shiu MN, Chen TH, Chang SH, Hahn LJ. Risk factors for leukoplakia and malignant transformation to oral carcinoma: a leukoplakia cohort in Taiwan. Br J Cancer 200o;82:1871-4

19. Zitterbart PA, Matranga LF, Christen AG et al. Association between cigarette smoking and the prevalence of dental caries in adult males. Gen Dent 1990;38(6):426-31.

20. Rennard SI, Daughton DM. Smoking cessation. Chest 2000;117: (5 Suppl 2):360S-364S

21. Jorenby DE, Leischow SJ, Nides MA, et al. A controlled trial of sustained-release bupropion, a nicotine patch, or both for smoking cessation. N Engl J Med 1999;340:685-91.

\section{AUTHOR AFFILIATIONS}

BDS, MDS, Oral Medicine and Radiology, Consultant Dental Surgeon

BDS, MDS, Public Health Dentistry, Private Practitioner 